\title{
PERBAIKAN MANAJEMEN KESELAMATAN DAN KESEHATAN KERJA (K3) DENGAN PENDEKATAN DMAIC BAGI PEKERJA PROYEK PEMBANGUNAN GEDUNG DI GRESIK
}

\author{
Titiek Koesdijati \\ Program Studi Teknik Industri, Fakultas Teknik, Universitas PGRI Adi Buana Surabaya \\ Email : titik@unipasby.ac.id
}

\begin{abstract}
Abstrak
Sistem manajemen K3 (Keselamatan dan Kesehatan Kerja) adalah bagian dai manajemen secara keseluruhan yang meliputi struktur organisasi, perencanaan, tanggung jawab, pelaksanaan, prosedur dan sumber daya yang dibutuhkan bagi pengembangan, penerapan pencapaian, pengkajian dan pengendalian resiko serta berkaitan dengan kegiatan kerja sehingga tercipta tempat kerja yang aman, efisien dan produktif. Tingkat keselamatan dan kesehatan kerja bagi proyek pembangunan gedung masih sering diabaikan sehingga dibutuhkan aturan atau Standar Operating Procedure (SOP) untuk mengurangi kejadian yang tidak diinginkan. Untuk memperbaiki sistem manajemen K3 yang sudah ada, menggunakan pendekatan DMAIC dan diawali dengan pengolahan data kuisener menggunakan SPSS. Hasil kuisener menunjukkan 67\% pada sikap pekerja. Sedangkan pengolahan data selanjutnya menunjukkan adanya potensi yang membahayakan pada alat, bahan dan mesin yang digunakan, terlihat dari diagram Pareto dan Ishikawa. Pendekata DMAIC menunjukkan kebutuhan untuk membuat SOP dilanjutkan dengan sosialisasi pelatihan bagi pekerja untuk mengurangi kecelakaan kerja.
\end{abstract}

Kata kunci : manajemen K3, Preto, Fishbone, DMAIC

\section{Abstract}

The K3 (Occupational Health and Safety) management system is part of the overall management which includes the organizational structure, planning, responsibilities, implementation, procedures and resources required for development, implementation of achievements, assessment and risk control as well as related to work activities so as to create a safe, efficient and productive workplace. The level of occupational safety and health for building construction projects is often neglected so that a standard operating procedure (SOP) is needed to reduce unwanted incidents. To improve the existing K3 management system, use the DMAIC approach and begin with processing the questionnaire data using SPSS. Questionnaire results showed 67\% of workers' attitudes. Meanwhile, further data processing shows the potential harm to the tools, materials and machines used, as seen from the Pareto and Ishikawa diagrams. The DMAIC approach shows the need to make SOP followed by socialization of training for workers to reduce work accidents.

Key Words: K3 management, Preto, Fishbone, DMAIC

\section{PENDAHULUAN}

Pengelolaan manajemen

pembangunan gedung seperti operasional produksi, bahan baku, sumber daya manusia, keuangan dan pemasaran tidak akan lengkap apabila tidak disertai dengan manajemen Keselamatan dan Kesehatan Kerja (K3). Sejak tahun 1980an para ahli K3 berupaya meyakinkan semua pihak khususnya manajemen organisasi perusahaan untuk menempatkan aspek manajemen K3 setara dengan unsur lain dalam organisasi. Hal inilah yang mendorong lahirnya berbagai konsep tentang K3 sebagai cara untuk melindungi para pekerja dan perusahaan.(Suhatman Ramli, 2010).

Menurut Kepmenaker nomer 05 tahun 1996, sistem manajemen K3 adalah 
bagian dari sistem manajemen perusahaan secara keseluruhan yang meliputi struktur organisasi, perencanaan, tanggung jawab, pelaksanaan, prosedur, proses dan sumber daya yang dibutuhkan bagi pengembangan, penerapan, pencapaian, pengkajian serta pengendalian resiko, yang semuanya ini berkaitan dengan kegiatan kerja guna terciptanya tempat kerja yang aman, efisien dan produktif (Soehatman Ramli, 2010).

Dari beerapa faktor penyebab terjadinya kecelakaan kerja maka rekayasa teknologi kesehatan dan keselamatan kerjaharus diterapkan sejak perencanaan, perancangan, konsruksi dan operasi hingga paska operasi. Disini permasalahannya apakah perlu membuat aturan Standart Operational Procedure (SOP), mengetahui prosedur dan mengidentifikasi potensi bahaya yang ada di lingkungan kerja, sudah terdapat rambu-rambu (safety sign) di area kerja serta bagaimana tindakan perusahaan apabila terdapat pekerja yang tidak mengindahkan aturan dan ketentuan yang telah ditetapkan perusahaan. Dengan demikian, tujuannya adalah membuat SOP tentang Kesehatan dan Keselamatan Kerja serta mengidentifikasi potensi bahaya yang ada di lingkungan kerja dilengkapi dengan tindakan perusahaan.

\section{METODE}

Pengambilan data dilakukan melalui kuisener dimana data tersebut diolah melalui aplikasi SPSS versi 16. Dari hasil pengolahan diperoleh uji validitas dan uji reliabilitas sehingga data yang digunakan reliabel. Langkah berikutnya menggunakan metode Six Sigma yaitu Define Measure Analysis Measure Improve Control (DMAIC). Metode Six Sigma merupakan suatu alat manajemen yang fokus pada pengendalian kualitas dengan mendalami system produksi secara keseluruhan. Ukuran nilai Six Sigma dinyatakan dalam DPU (Defect Per Unit) atau PPM (Part Per Million). Semakin tinggi nilai Sigma maka semakin baik pula kualitasnya atau semakin rendah nilai kecacatan, kegagalannya.

Tahapan yang digunakan dalam menggunakan metode DMAIC yaitu :

1. Define : mendefinisikan dan menyeleksi permasalahan terkait dengan Keselamatan dan Kesehatan Kerja beserta dampaknya, mengambil data kuisenesr dari 100 orang pekerja

2. Measure : melakukan pengukuran terhadap permasalahan yang dialami pekerja dengan memonitoring kedisiplinan dalam bekerja, cara penggunaan APD (Alat Pelindung Diri) yang baik dan benar dan kepatuhan terhadap standart K3.

3. Analysis : untuk menemukan solusi dengan mencari akar penyebab dari permasalahan yang terjadi

4. Improve : digunakan dalam melakukan tindakan perbaikan terhadap permasalahan yang terjadi pada kegiatan kerja karyawan, dengan cara pembuatan Standart Kelengkapan Kerja, SOP bagi penerimaan pekerja baru dan Karti Ijin Bekerja (KIB)

5. Control : melakukan pengawasan pada pekerja dengan berkeliling untuk megetahui apakah pekerja sudah mengikuti aturan dan menggunakan APD

\section{HASIL DAN PEMBAHASAN}

\section{a. Deskripsi Responden}

Berdasarkan usia diketahui bahwa 75 responden yang menjawab berusia antara 27 sampai 40 tahun, yang terbanyak 14 orang berusis 30 tahun dan paling sedikit 1 orang berusia 38 tahun.

Berdasarkan jenis kelamin, responden semua laki-laki yang bekerja di lapangan, sedangkan yang wanita di bagian adminstrasi dan jumlahnya sedikit.

Berdasarkan masa kerja 1 sampai 6 tahun diketahui 24 orang mempunyai masa kerja 3 tahun dan 2 orang dengan masa kerja 6 tahun.

Berdasarkan pembagian pekerjaan responden, 60 orang sebagai kuli dan 15 orang sebagai tukang

\section{b. Hasil Kuisener}

Hasil kuisioner yang telah dilakukan menunjukan bahwa pelaksanaan K3 dan penerapan sikap menunjukan angka tertingggi dari beberapa aspek yang ada. Secara lengkap hasil kuisioner ditunjukan pada gambar 1 dan 2 berikut. 


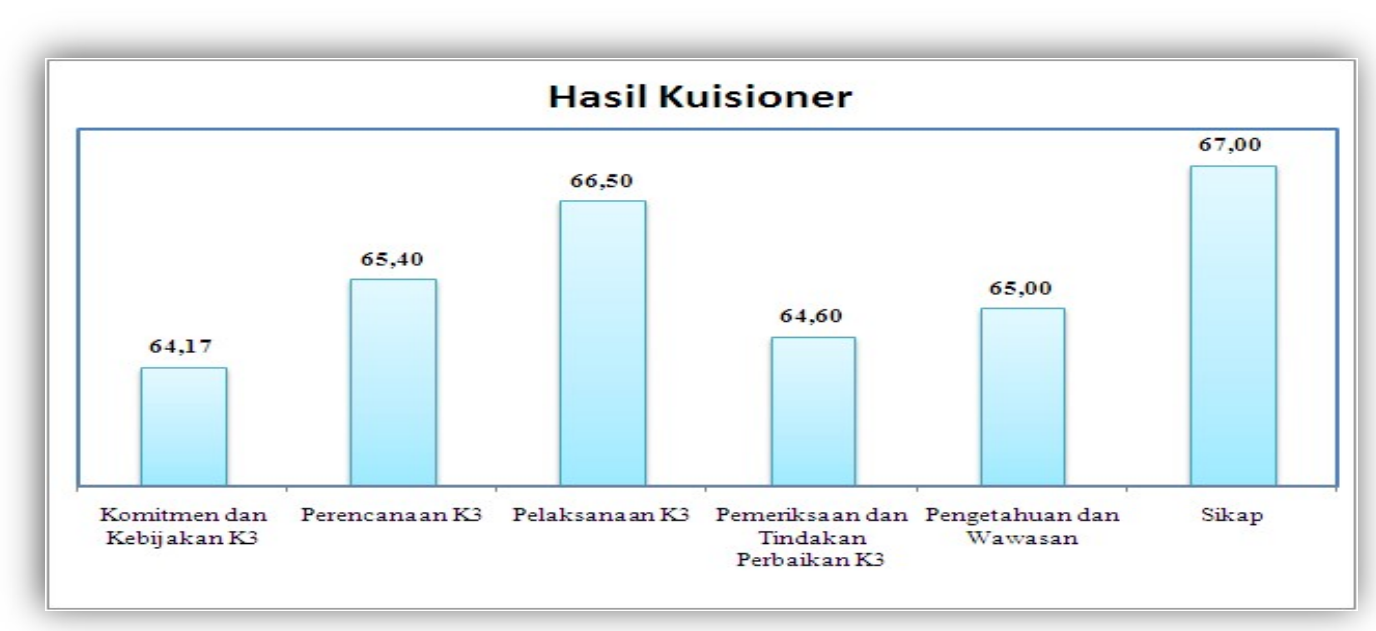

Gambar 1. Sistem Manajemen K3

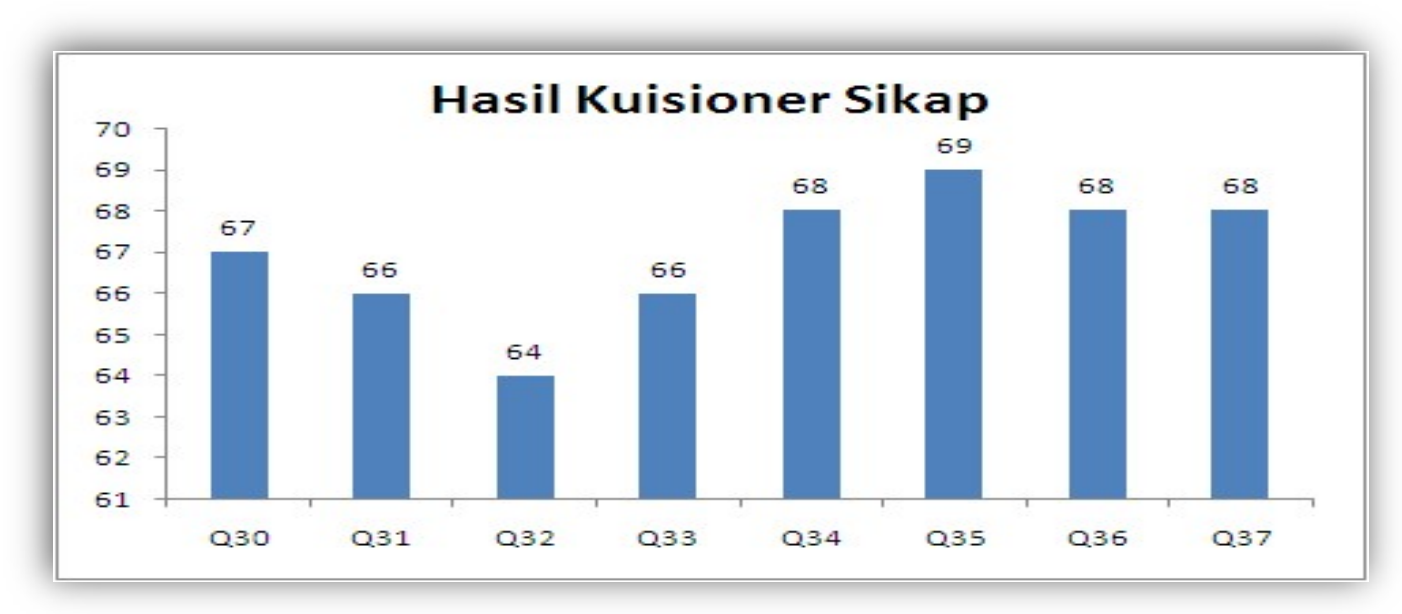

Gambar 2. Pekerja Proyek Pembangunan

Gambar 1 diketahui bahwa hasil kuisener untuk Sistem Manajemen K3 yang tertinggi adalah Sikap dari Pekerja sebesar $67 \%$, diikuti Pelaksanaan K3 66,5\%, Perencanaan K3 65,40\%, Pengetahuan dan Wawasan 65\%, Pemeriksaan dan Tindakan Perbaikan K3 64,6\%, Komitmen dan Kebijakan K3 64,17\%

Sedangkan dari gambar 2 untuk Pekerja Proyek Pembangunan diketahui jumlah responden yang menjawab berdasarkan dimensi pertanyaan Q1 sampai Q7, yang dibagi menjadi bagian Pengetahuan dan Wawasan tentang K3 dan Sikap menghadapi pelaksanaan K3.

\section{c. Uji Validitas dan Reliabilitas}

Uji Validitas yang dilakukan pada data kuisener Sistem Manajemen K3 dengan r table $=0,2272$ menunjukkan bahwa pada 20 pertanyaan tersebut 17 pertanyaan dinyatakan valid dengan $r$ hitung lebih tinggi dari $r$ table. Sedangkan uji validitas pada kuisener Pekerja Proyek Pembangunan menunjukkan bahwa dari 17 pertanyaan yang dinyatakan valid adalah 14 pertanyaan. Hasil perhitungan Reliabilitas pada nilai Alpha Cronbach diperoleh hasil yang lebih tinggi dari $r$ table 0,2272 yaitu 0,736 untuk Sistem Manajemen K3 dan 0,641 untuk Pekerja Proyek Pembangunan.

\section{d. Diagram Pareto dan diagram Fishbone Hasil kuisener secara keseluruhan menunjukkan bahwa bagian Sikap Pekerja yang setuju terbanyak terhadap perbaikan perlu mendapat perhatian seperti yang tersaji pada gambar 3.}




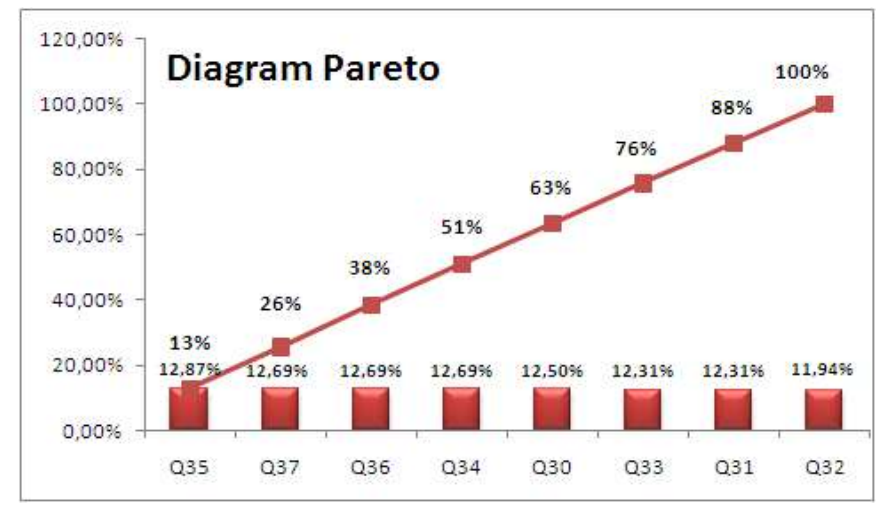

Gambar 3. Diagram Pareto Sikap Pekerja

Pada gambar 3 tentang pengolahan data melalui diagram Pareto yang digambarkan dari Q30 sampai Q37, sesuai dengan table 2, Sikap Pekerja Proyek Pembangunan dan

ternyata terdapat prioritas yang harus diperhatikan dan mendapat penyelesaian yaitu Q35.

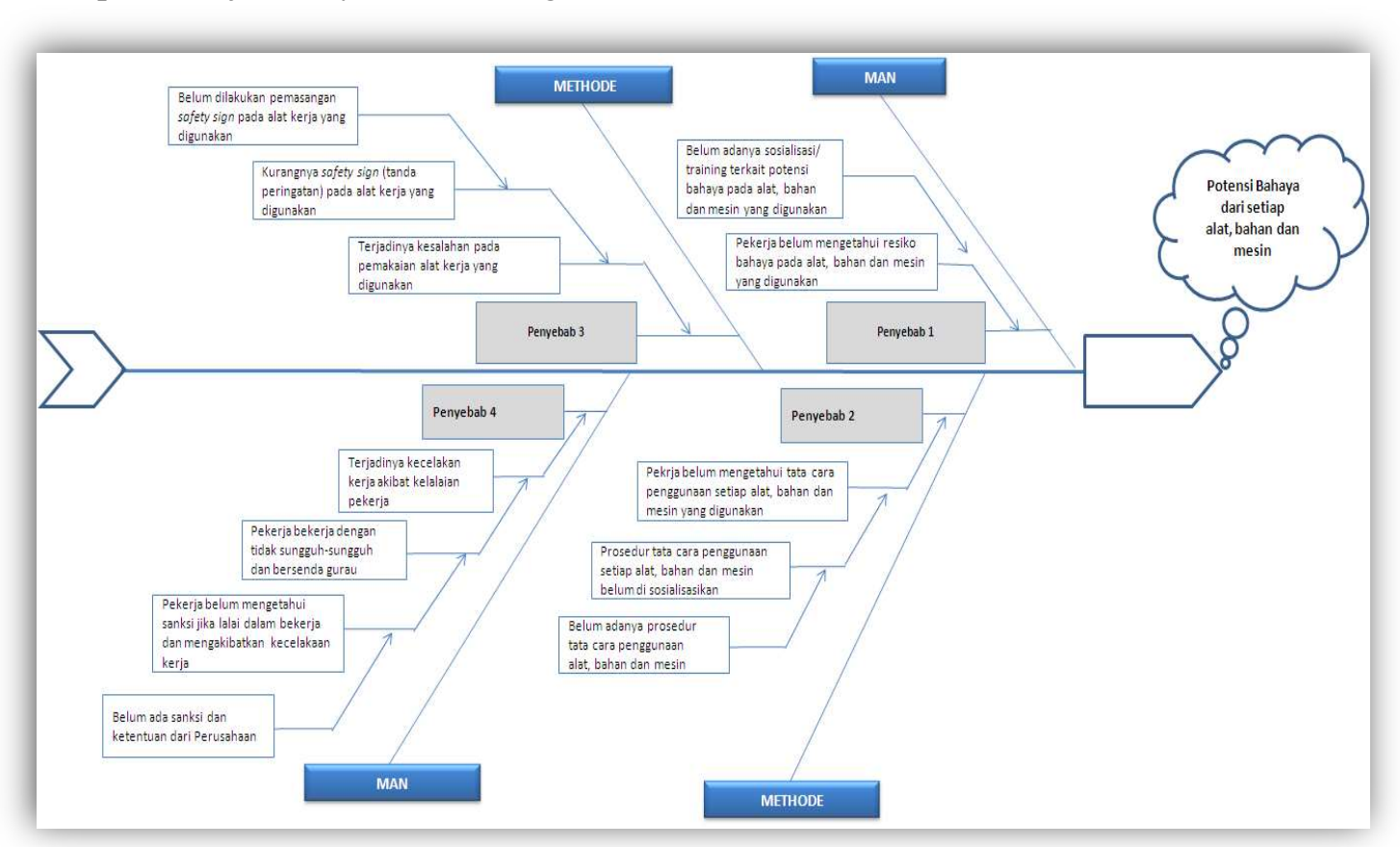

Gambar 4. Diagram Fishbone Sikap Pekerja

Selanjutnya diagram Fishbone pada gambar 4 menguraikan penyebab masalah dari Sikap Pekerja Proyek Pembangunan ditinjau dari potensi bahaya bagi pekerja. Uraian untuk penyebabnya adalah
a. Man : kurangnya sosialisasi tentang bahaya dan penanggulangannya, belum mengetahui resiko yang terjadi
b. Methode : belum mengetahui standart pemakaian alat dan bahan

c. Material : belum mengetahui kegunaan dan ukuran pemakaian

d. Environement : kurangnya tanda peringatan bahaya (safety sign)
e. Machine : belum mengetahui penggunaan alat yang benar

e. DMAIC (Demain Measure Analise Improve Control)

1. Tahap Demain 
Pada tahap Demain ini dapat dijelaskan melalui gambar 2 tentang diagram Pareto terhadap sikap pekerja. Prioritas yang perlu mendapat perhatian adalah Q35 yaitu sebesar $12,87 \%$ karena mempunyai prosentase tertinggi.

2. Tahap Measure

Tahap Measure sebagai tindak lanjut dari tahap Demain yaitu dengan mencari penyebabnya, dapat dijelaskan melalui diagram Fishbone pada gambar 3. Secara umum dapat diketahui penyebabnya adalah a. Belum adanya sosialisasi/training terkait potensi bahaya pada alat, bahan dan mesin yang digunakan.

b. Belum adanya prosedur tata cara penggunaan alat, bahan dan mesin.

c. Belum dilakukan pemasangan safety saign pada tempat dan alat kerja yang digunakan.

d. Belum ada sanksi dan ketentuan dari perusahaan.

\section{Tahap Analysis}

Pada tahap Analysis ini dilakukan pemahan terhadap rencana proses dan pelaksanaannya setelah diketahui penyebabnya

\begin{tabular}{|c|c|c|}
\hline NO & PENYEBAB & PENYELESAIAN \\
\hline 1 & $\begin{array}{l}\text { Belum } r \text { adanya } \\
\text { sosialisasi/training terkait } \\
\text { potensi bahaya pada alat, } \\
\text { bahan dan mesin yang } \\
\text { digunakan. }\end{array}$ & $\begin{array}{l}\text { Melakukan sosialisasi /pelatihan untuk para pekerja } \\
\text { terkait K3 agar paham dan mengerti tentang cara } \\
\text { mengidentifikasi bahaya pada lingkungan kerja } \\
\text { masing-masing terutama pada alat, bahan, mesin } \\
\text { yang digunakan dan dilanjutkan cara mengatasinya }\end{array}$ \\
\hline 2 & $\begin{array}{l}\text { Belum adanya prosedur tata } \\
\text { cara penggunaan alat, bahan } \\
\text { dan mesin. }\end{array}$ & $\begin{array}{l}\text { Membuat prosedur tata cara penggunaan alat, } \\
\text { bahan dan mesin agar pengguna atau pekerja } \\
\text { mengetahui dan mempersiapkan Alat Pelindung } \\
\text { Diri (APD) yang sesuai dan akan digunakan } \\
\text { sebelum memulai aktifitas pekerjaannya }\end{array}$ \\
\hline 3 & $\begin{array}{l}\text { Belum dilakukan pemasangan } \\
\text { safety saign pada tempat dan } \\
\text { alat kerja yang digunakan }\end{array}$ & $\begin{array}{l}\text { Melakukan pemasangan safety sign atau rambu- } \\
\text { rambu pada alat kerja atau lokasi pekerjaan yang } \\
\text { memvabahayakan bagi pekerja, tujuannya untuk } \\
\text { mengingatkan bahaya dan resiko yang terjadi. }\end{array}$ \\
\hline 4. & $\begin{array}{l}\text { da sanksi dan } \\
\text { in dari perusahaan. }\end{array}$ & $\begin{array}{l}\text { Membuat sansi dan ketentuan bagi pekerja yang } \\
\text { melakukan pelnggaran atau kelalaian pada saat } \\
\text { bekerja, bertujuan untuk mengurangi angka } \\
\text { kecelakaan dan efek jera pada seluruh pekerja yang } \\
\text { tidak mengikuti aturan atau ketentuan perusahaan }\end{array}$ \\
\hline
\end{tabular}

4. Tahap Improve

Pada tahap improve ini dilakukan perencanaan dan penjadwalan berkaitan dengan rencana penyelesaian yang sudah dibuat tahap Analyse.

\begin{tabular}{lll}
\hline NO & \multicolumn{1}{c}{ PENYELESAIAN } & \multicolumn{1}{c}{ PELAKSANAAN } \\
\hline 1 & $\begin{array}{l}\text { Melakukan sosialisasi /pelatihan } \\
\text { untuk para pekerja terkait K3 agar } \\
\text { paham dan mengerti tentang cara } \\
\text { mengidentifikasi bahaya pada } \\
\text { lingkungan kerja masing-masing } \\
\text { terutama pada alat, bahan, mesin } \\
\text { yang digunakan dan dilanjutkan cara } \\
\text { mengatasinya }\end{array}$ & $\begin{array}{l}\text { Melakukan penjadwalan secara } \\
\text { berkala sosialisasi /pelatihan K3 bagi } \\
\text { para pekerja }\end{array}$ \\
& \\
Membuat prosedur tata cara & \\
penggunaan alat, bahan dan mesin & Membuat WI (Work Instruction) atau \\
& & SOP (Standar Operating Procedure)
\end{tabular}


agar pengguna atau pekerja mengetahui dan mempersiapkan Alat Pelindung Diri (APD) yang sesuai dan akan digunakan sebelum memulai aktifitas pekerjaannya

3 Melakukan pemasangan safety sign atau rambu-rambu pada alat kerja atau lokasi pekerjaan yang memvabahayakan bagi pekerja, tujuannya untuk mengingatkan bahaya dan resiko yang terjadi

4. Membuat sanksi dan ketentuan bagi pekerja yang melakukan pelnggaran atau kelalaian pada saat bekerja, bertujuan untuk mengurangi angka kecelakaan dan efek jera pada seluruh pekerja yang tidak mengikuti aturan atau ketentuan perusahaan

\section{Tahap Control}

Pada tahap Control ini dilakukan pengawasa melalui SOP yang ada. Secara rutin diperiksa oleh tim Safety Officer perusahaan dan dilaporkan pada manajemen perusahaan

Setelah melalui penelitian dengan menggunakan metode DMAIC maka pekerja yang melakukan pekerjaan akan berhati-hati dan harus disiplin sesuai dengan aturan yang ada. Perusahaan juga membentuk tim untuk merencanakan sosialisasi /pelatihan K3 dan membuat kelengkapan yang dibutuhkan seperti WI, SOP, Karu Pekerja dan sebagainya. Dengan demikian pengurangan angka kecelakaan kerja dapat dikurangi.

\section{KESIMPULAN}

Pada penelitian ini, Sistem Manajemen Keselamatan dan Kesehatan Kerja (K3) mempunyai peranan penting dalam perusahaan. Hasil kuisener Sistem Manajemen K3 prosentase tertinggi adalah Sikap dari Pekerja sebesar 67\%. Melalui diagram Fishbone diperoleh pernyataan kurangnya sosialisasi tentang bahaya dan penanggulangannya, belum mengetahui resiko yang terjadi belum mengetahui standart pemakaian alat dan bahan, belum mengetahui terkait tata cara penggunaan APD dan

pengoperasian alat serta

mengharuskan pekerja untuk mentaati

Membuat dan menempelkan peringatan tentang safety sign atau rambu-rambu peringatan di setiap lokasi kerja dan melengkapi peralatanperalatan untuk mengatasi bahaya seperti kebakaran, tersengat listrik dan sebagainya

Membuat Kartu Ijin Bekerja bagi setiap pekerja yang harus dipakai pada saat berada di lokasi kerja dimana pada kartu menunjukkan data pekerja seperti sudah mengikuti pelatihan, melakukan kesalahan dan sebagainya

kegunaan dan ukuran pemakaian kurangnya tanda peringatan bahaya (safety sign), belum mengetahui penggunaan alat yang benar.

Melalui DMAIC dapat diketahui untuk melakukan penjadwalan secara berkala sosialisasi /pelatihan K3 bagi para pekerja, membuat WI (Work Instruction) atau SOP (Standar Operating Procedure) terkait tata cara penggunaan APD dan pengoperasian alat serta mengharuskan pekerja untuk mentaati, membuat dan menempelkan peringatan tentang safety sign atau rambu-rambu peringatan di setiap lokasi kerja dan melengkapi peralatan-peralatan untuk mengatasi bahaya seperti kebakaran, tersengat listrik dan sebagainya, membuat Kartu Ijin Bekerja bagi setiap pekerja yang harus dipakai pada saat berada di lokasi kerja dimana pada kartu menunjukkan data pekerja seperti sudah mengikuti pelatihan, melakukan kesalahan dan sebagainya

\section{Ucapan Terima Kasih}

Ucapan terima kasih disampaikan kepada LPPM Universitas PGRI Adi Buana Surabaya yang telah mendukung penuh kegiatan penelitian ini sehingga dapat terselesaikan dengan baik dan tepat waktu. 


\section{Daftar Pustaka}

Hidayat, Yayan Farid Poniman 2015, Manajemen HR, Edisi Pertama, PT Gramedia Pustaka Utama, Jakarta.

Kuswana, Wowo Sunaryo 2014, Ergonomi dan K3, Edisi Pertama, PT Remaja Rosdakarya, Bandung. (Burton et al 1978)

Ramli, Soehatman 2010, Sistem Manajemen Keselamatan dan Kesehatan Kerja OHSAS 18001, Edisi Pertama, Dian Rakyat, Jakarta.
Sujarweni, V. Wiratna 2014, Metodologi Penelitian, Edisi Pertama, Pustakabarupres, Yogyakarta.

Suma'mur PK, Soedirman 2014, Kesehatan Kerja Dalam Perspektif Hiperkes \& Keselamatan Kerja, Edisi Pertama, Erlangga, Jakarta.

Ahdi 2014, Peraturan K3 Keselamatan dan Kesehatan Kerja bekerja di Proyek, 16 Desember 2016

Jurnal Berkala, 2015, Analisis Manajemen Resiko Kesehatan dan Kesehatan Kerja (K-3) Dalam Penggunaan Las Pada Proyek Instalasi Pipa PT.Citra Adikarya Teknik Surabaya. 